\title{
Co-ETS-10 and Co-AM- 6 as active catalysts for the oxidation of styrene to styrene oxide and benzaldehyde using molecular oxygen
}

\author{
Shuvo Jit Datta, Kyung Byung Yoon* \\ Korea Center for Artificial Photosynthesis, Center for Nano Materials, Department of Chemistry, Sogang University, Seoul 121-742, Republic of Korea
}

\section{A R T I C L E I N F O}

Article history:

Received 2 March 2015

Accepted 16 April 2015

Published 20 June 2015

\section{Keywords:}

Heterogeneous catalysis

Epoxidation

Cobalt

$\mathrm{C}=\mathrm{C}$ activation

Zeolite

\begin{abstract}
A B S T R A C T
Pristine ETS-10 and AM-6 and their $\mathrm{Co}^{2+}$-exchanged forms were prepared, and their catalytic activities toward the oxidation of styrene in oxygen atmosphere were studied in dimethylformamide. The catalysts were denoted as Co-E10- $n(n=0,9,26,68,81)$ and Co-A6- $m(m=0,8,23,63,79)$, where $n$ and $m$ denote the degree of $\mathrm{Co}^{2+}$ exchange. The products of the oxidation process were identified as styrene epoxide (E) and benzaldehyde (B). Both the pristine forms, ETS-10 (Co-E10-0) and AM-6 (Co-A6-0), and $\mathrm{Co}^{2+}$-exchanged forms displayed catalytic activities. With increasing $n$ or $m$, the conversion, and hence the rate, increased. Specifically, the rates varied from 6.1 to $12.5 \mathrm{mmol} \cdot \mathrm{g}^{-1} \cdot \mathrm{h}^{-1}$ with increasing $n$ (Co-E10- $n$ catalysts) and from 5.4 to $12.4 \mathrm{mmol} \cdot \mathrm{g}^{-1} \cdot \mathrm{h}^{-1}$ with increasing $m$ (Co-A6- $m$ catalysts). In contrast, the E/B ratio decreased with increasing $n$ or $m$. More specifically, the E/B ratio decreased from 2.1 to 0.1 with increasing $n$ from 0 to 81 (Co-E10- $n$ catalysts) and from 1.3 to 0.1 with increasing $m$ from 0 to 79 (Co-A6- $m$ catalysts). Co-E10-9 displayed the highest $\mathrm{E}$ yield and Co-A6-79 generated the highest $\mathrm{B}$ yield. The highest turnover frequency obtained was $36.3 \mathrm{Co}^{-1} \cdot \mathrm{h}^{-1}$, which was the highest one obtained among those obtained for the $\mathrm{Co}^{2+}$-exchanged zeolites and mesoporous silica reference materials studied in this work.
\end{abstract}

(C) 2015, Dalian Institute of Chemical Physics, Chinese Academy of Sciences. Published by Elsevier B.V. All rights reserved.

\section{Introduction}

The catalytic oxidation of olefins in the presence of molecular $\mathrm{O}_{2}$ is highly attractive from economic and environmental viewpoints. Particularly, the partial oxidation of olefins to epoxides and aldehydes is an industrially important reaction because epoxides and aldehydes are widely used as the precursors and intermediates for the syntheses of various fine chemicals and useful chemical products in the pharmaceutical, resin, and paint industries [1-4].

In principle, the direct oxidation of olefins with $\mathrm{O}_{2}$ is highly unfavorable because the ground state of $\mathrm{O}_{2}$ is a triplet, whereas the ground states of olefins are singlets. Accordingly, the oxidation of olefins with $\mathrm{O}_{2}$ has generally been performed in the co-presence of reductants such as $\mathrm{H}_{2}$, alcohols, and aldehydes. However, Tang et al. [5,6] first demonstrated that $\mathrm{Co}^{2+}$-exchanged faujasite-type zeolites could effectively catalyze the oxidation of styrene with $\mathrm{O}_{2}$ in the absence of reductants. Consequently, subsequent studies focused on the catalytic activities of various Co-exchanged and Co-containing microporous and mesoporous materials such as alkali and alkaline metal-modified Co-X [7], Co-Y [8], Co-SSZ-51 [9], Co-SBA-15 [10], Co-ZSM-5 [11-13], Co-SAPO-5 and Co-SAPO-34 [14], Co-MOR, Co-5A [15], and Co-coordinated

\footnotetext{
* Corresponding author. Tel: +082-2-7152569; Fax: +082-2-7064269; E-mail: yoonkb@sogang.ac.kr This work was supported by the Ministry of Science, ICT and Future Planning through the National Research Foundation of Korea (no. 2009-0093886, no. 2012R1A2A3A01009806). DOI: 10.1016/S1872-2067(15)60864-6 | http://www.sciencedirect.com/science/journal/18722067 | Chin. J. Catal., Vol. 36, No. 6, June 2015
} 
organic-inorganic hybrid catalysts [16] toward the oxidation of olefins with $\mathrm{O}_{2}$ or air. Among them, Co-X, Co-Y, and Co-SBA-15 $[5-8,10]$ were effective in the epoxidation of olefins with molecular $\mathrm{O}_{2}$. Co-SSZ-51 was also active, but required higher $\mathrm{O}_{2}$ pressures (> 4.14 bar) [9]. Conversely, other catalysts (Co-ZSM-5, Co-SAPO-5, Co-SAPO-34, Co-MOR, Co-5A, and Co-coordinated organic-inorganic hybrid material) required substantial amounts of initiators, such as tert-butyl hydroperoxide or cumyl hydroperoxide, to achieve high conversions [11-16]. Thus, the development of more active catalysts that do not require initiators in the target catalytic process is of interest.

ETS-10 is a unique titanosilicate that constitutes regularly spaced $\mathrm{TiO}_{3}{ }^{2-}$ quantum wires with diameters $(d)$ of $\sim 0.67 \mathrm{~nm}$ (Fig. 1(a)). Furthermore, the structure comprises corner-sharing $\mathrm{SiO}_{4}$ tetrahedra and $\mathrm{TiO}_{6}$ octahedra linked via bridging oxygen atoms [17-19]. Formation of the structure can be described as an intergrowth of two hypothetical ordered Polymorph A (not shown) and Polymorph B (Figs. 1(b),(c)). Polymorph A has identical projection along the (100) and (010) directions to that of Polymorph B along the (110) and (110) directions. In Polymorph $\mathrm{B}$, the $\mathrm{TiO}_{3}{ }^{2-}$ quantum wires run along the (110) and (110) directions in the crystal (Figs. 1(b),(c)). Each $\mathrm{TiO}_{3}{ }^{2-}$ quantum wire is surrounded by nanoporous silica (Fig. 1(d)), with a pore dimension of $8 \times 5 \AA^{2}$. The pore structure of ETS-10 contains 12 rings in all three dimensions. Only a few microporous zeolites with a three-dimensional 12-ring pore system are known, and in this aspect ETS-10 has excellent diffusion characteristics. It is important to point out that the structure is inherently an intergrowth structure, consisting of randomly stacked layers. The basic unit is $\mathrm{Si}_{40} \mathrm{Ti}_{8} \mathrm{O}_{104}{ }^{16-}$, which is counterbalanced by 16 monovalent $\left(\mathrm{Na}^{+}\right.$and $\left.\mathrm{K}^{+}\right)$cations. These counter cations can be exchanged with various other (a)

(c)

ETS-10 or AM-6

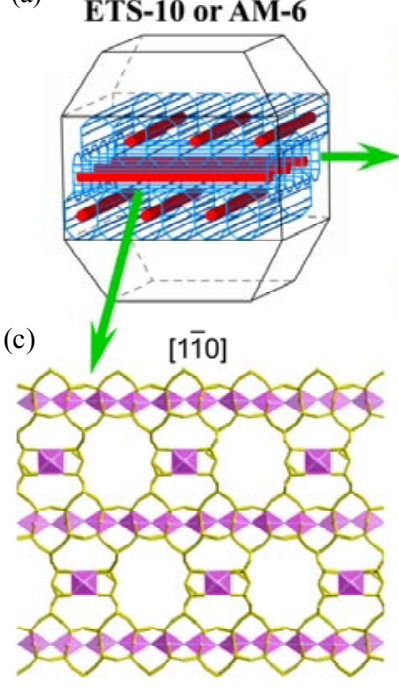

(b)

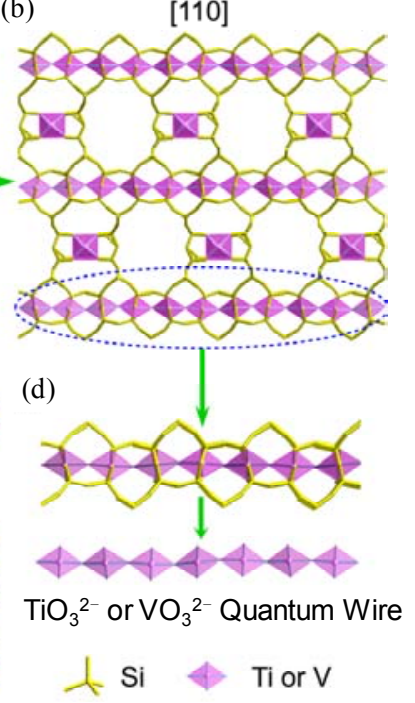

Fig. 1. (a) Schematic illustration of the structure of ETS-10 or AM-6 imbedded with a three dimensional networks of $\mathrm{SiO}_{2}$ channels (blue) and $\mathrm{TiO}_{3}{ }^{2-}$ or $\mathrm{VO}_{3}{ }^{2-}$ molecular wires (red) in case of polymorph $\mathrm{B}$. (b) View along the (110) axis. (c) View along the [110] axis. (d) A single $\mathrm{TiO}_{3}{ }^{2-}$ or $\mathrm{VO}_{3}{ }^{2-}$ molecular wire (pink) surrounded by silica (gold) and a single $\mathrm{TiO}_{3}{ }^{2-}$ or $\mathrm{VO}_{3}{ }^{2-}$ molecular wire. monovalent, divalent, or trivalent cations through ion exchange. AM-6 is isostructural to ETS-10, featuring $\mathrm{VO}_{3}{ }^{2-}$ quantum wires instead of $\mathrm{TiO}_{3}{ }^{2-}$ quantum wires $[20,21]$.

To date, only Co-exchanged aluminosilicates have been examined as olefin oxidation catalysts. Therefore, expanding this research area by examining the catalytic activities of titanosilicate (ETS-10), vanadosilicate (AM-6), and their Co-exchanged forms is of interest to explore the role of the titanate and vanadate quantum wires within the structures. Herein, we report the catalytic performances of ETS-10, AM-6, and their $\mathrm{Co}^{2+-}$ exchanged forms featuring varying degrees of $\mathrm{Co}^{2+} \mathrm{ex}^{-}$ change toward the oxidation of styrene with $\mathrm{O}_{2}$ to styrene epoxide (E) and benzaldehyde (B).

\section{Experimental}

\subsection{Materials}

$\mathrm{Na}_{2} \mathrm{SiO}_{3}\left(17 \%-19 \% \mathrm{Na}_{2} \mathrm{O}\right.$, and $35 \%-38 \% \mathrm{SiO}_{2}$, Kanto), titanium isopropoxide (98\%, Junsei), $\mathrm{V}_{2} \mathrm{O}_{5}$ (99\%, Aldrich), $\mathrm{H}_{2} \mathrm{SO}_{4}$ (95\%, Duksan), NaOH, (93\%-100\%, Samchun), KF (95\%, Samchun), $\mathrm{Co}\left(\mathrm{CH}_{3} \mathrm{COO}\right)_{2} \cdot 4 \mathrm{H}_{2} \mathrm{O}$ (Junsei), styrene (99\%, Sigma-Aldrich), styrene oxide (97\%, Aldrich), benzaldehyde (99\%, Sigma-Aldrich), ethanol (95\%, SK), and $N, N$-dimethylformamide (DMF, 99\%, Samchun) were purchased and used without further purification.

\subsection{Synthesis of ETS-10 with sizes of 200-300 nm}

A $\mathrm{Si}$ source solution was first prepared by dissolving $\mathrm{Na}_{2} \mathrm{SiO}_{3}$ (18.4 g) in $\mathrm{H}_{2} \mathrm{O}$ (60 g), to which $\mathrm{NaOH}$ aqueous solution (2.4 $\mathrm{g} \mathrm{NaOH}$ and $20 \mathrm{~g} \mathrm{H}_{2} \mathrm{O}$ ) was added with vigorous stirring, and the mixture was stirred for $2 \mathrm{~h}$. For the preparation of the Ti source solution, titanium isopropoxide (5.7 g), $\mathrm{H}_{2} \mathrm{SO}_{4}$ (4.5 g), and $\mathrm{H}_{2} \mathrm{O}(35 \mathrm{~g})$ were mixed together and boiled at $100{ }^{\circ} \mathrm{C}$ for 90 min, and allowed to cool to room temperature. The Ti source solution was added dropwise to the $\mathrm{Si}$ source solution, and the mixture was stirred for $1 \mathrm{~h}$. A dilute $\mathrm{KF}$ solution $1.2 \mathrm{~g} \mathrm{KF}$ and $15 \mathrm{~g} \mathrm{H}_{2} \mathrm{O}$ ) was added to the above mixture. The mixture was aged for $16 \mathrm{~h}$ at room temperature and transferred to a Teflon-lined autoclave, and heated at $200{ }^{\circ} \mathrm{C}$ for $22 \mathrm{~h}$ under static conditions. After cooling the autoclave to room temperature, the crystals were collected by centrifugation and washed with copious amounts of distilled deionized water.

\subsection{Synthesis of AM-6 with sizes of $150-250 \mathrm{~nm}$}

To prepare the $\mathrm{Si}$ source solution, a $\mathrm{NaOH}$ solution (3 g $\mathrm{NaOH}$ and $20 \mathrm{~g} \mathrm{H}_{2} \mathrm{O}$ ) was added to the sodium silicate solution composed of $\mathrm{Na}_{2} \mathrm{SiO}_{3}$ (12.2 g) and $\mathrm{H}_{2} \mathrm{O}$ (50 g).

To prepare the $\mathrm{V}$ source solution, a required amount of $\mathrm{H}_{2} \mathrm{SO}_{4}$ (4.5 g) was added to a 50-mL round-bottom flask containing $\mathrm{H}_{2} \mathrm{O}$ (10 g). Subsequently, $\mathrm{V}_{2} \mathrm{O}_{5}$ (1.4 g) and ethanol (4 g) were sequentially added to the flask. The heterogeneous mixture was refluxed for $25 \mathrm{~min}$.

Subsequently, the greenish-yellow $\mathrm{V}$ source solution was added dropwise to the Si source solution. A dilute KF solution 
( $2 \mathrm{~g} \mathrm{KF}$ and $10 \mathrm{~g} \mathrm{H}_{2} \mathrm{O}$ ) was added to the above mixture. After aging the mixture for $15 \mathrm{~h}$ at room temperature, the resulting gel was transferred to a 50-mL Teflon-lined autoclave, which was placed in a preheated oven at $220^{\circ} \mathrm{C}$ for $16 \mathrm{~h}$ under static conditions. The precipitated crystals were collected, washed, and dried at $100{ }^{\circ} \mathrm{C}$ for $1 \mathrm{~h}$.

\subsection{Preparation of Co-exchanged ETS-10 with varying degrees of $\mathrm{Co}^{2+}$ exchange (Co-E10- $n ; n=0,9,26,68,81$ )}

$\mathrm{Co}^{2+}$-exchanged ETS-10 powders with varying ion exchange degrees of $0,9 \%, 26 \%, 68 \%$, and $81 \%$ were prepared. Pristine ETS-10 is denoted as Co-E10-0. For the preparation of Co-E10-9, Co-E10-26, and Co-E10-68, pristine ETS-10 (1 g) was mixed with $\mathrm{Co}\left(\mathrm{CH}_{3} \mathrm{CO}_{2}\right)_{2}$ solution $(50 \mathrm{~mL})$ at varying concentrations of 4,10 , and $50 \mathrm{mmol} / \mathrm{L}$, respectively. The ion exchange was conducted at $50{ }^{\circ} \mathrm{C}$ for $1 \mathrm{~h}$. For the preparation of Co-E10-81, the ion-exchange was conducted thrice with 100 $\mathrm{mL}$ of $50 \mathrm{mmol} / \mathrm{L} \mathrm{Co}\left(\mathrm{CH}_{3} \mathrm{CO}_{2}\right)_{2}$ solution. All samples were washed with copious amounts of water and dried in an oven at $90^{\circ} \mathrm{C}$ for $2 \mathrm{~h}$.

2.5. Preparation of $\mathrm{CO}^{2+}$-exchanged $\mathrm{AM}-6$ with varying degrees of $\mathrm{Co}^{2+}$ exchange (Co-A6- $m$; $m=0,8,23,63,79$ )

$\mathrm{Co}^{2+}$-exchanged AM- 6 with varying ion exchange degrees of $0,8 \%, 23 \%, 63 \%$, and $79 \%$ were prepared. Pristine AM-6 is denoted as Co-A6-0. For the preparation of Co-A6-8, Co-A6-23, and Co-A6-63, pristine AM-6 (1 g) was mixed with $\mathrm{Co}\left(\mathrm{CH}_{3} \mathrm{CO}_{2}\right)_{2}$ solution $(50 \mathrm{~mL})$ at varying concentrations of 4,10 , and 50 $\mathrm{mmol} / \mathrm{L}$, respectively. The ion exchange was conducted at $50{ }^{\circ} \mathrm{C}$ for $1 \mathrm{~h}$. For the preparation of Co-A6-79, the ion-exchange was conducted thrice with $100 \mathrm{~mL} \mathrm{Co}\left(\mathrm{CH}_{3} \mathrm{CO}_{2}\right)_{2}$ solution (50 $\mathrm{mmol} / \mathrm{L})$. All samples were washed with copious amounts of water and dried in an oven at $90^{\circ} \mathrm{C}$ for $2 \mathrm{~h}$.

\subsection{Characterization}

Scanning electron microscopy (SEM) images were obtained using a field-emission scanning electron microscope (Hitachi S-4300) operating at an acceleration voltage of $20 \mathrm{kV}$. Powder $\mathrm{X}$-ray diffraction (XRD) patterns were recorded on a Rigaku D/MAX-2500/pc diffractometer using $\mathrm{Cu} K_{\alpha}(\lambda=0.154056 \mathrm{~nm})$ radiation operating at $40 \mathrm{kV}$ and $200 \mathrm{~mA}$. The diffractograms were recorded in the $2 \theta$ range of $3^{\circ}-50^{\circ}$ with a step width of $0.02^{\circ}$ and $1^{\circ} / \mathrm{min}$ in continuous mode. The BET surface areas of the samples were determined using $\mathrm{N}_{2}$ adsorption-desorption performed at $-196{ }^{\circ} \mathrm{C}$ on a BELSORP-MAX analyzer. The samples were evacuated at $200{ }^{\circ} \mathrm{C}$ for $10 \mathrm{~h}$ prior to analysis. Raman spectra of the samples were recorded on an in-house-built setup equipped with $\mathrm{Ar}^{+}$ion laser (Spectra-Physics Stabilite 2017) as an excitation beam source, a spectrometer (Horiba JobinYvon TRIAX 550), and a CCD detector (Horiba JobinYvon Symphony) cooled at $-196{ }^{\circ} \mathrm{C}$. The wavelength of the excitation beam was $514.5 \mathrm{~nm}$. The diffuse reflectance UV-Vis spectra of the samples were recorded on a Varian Cary 5000 UV-Vis-NIR spectrophotometer equipped with an integrating sphere. Bar- ium sulfate was used as the reference. The diffuse reflectance spectra were converted using the Kubelka-Munk (K-M) function. Elemental analyses of the samples for $\mathrm{Na}^{+}, \mathrm{K}^{+}, \mathrm{Co}^{2+}, \mathrm{Si}, \mathrm{Ti}$, and $\mathrm{V}$ were conducted via energy-dispersive X-ray (EDX) spectroscopy analysis of the samples using an X-Max EDS-detector from Oxford instruments attached to a scanning electron microscope (JEOL-JSM-7600F).

\subsection{Oxidation of styrene with molecular $\mathrm{O}_{2}$}

Co-E10- $n$ and Co-A6- $m$ powders were vacuum dried at 150 ${ }^{\circ} \mathrm{C}$ for $10 \mathrm{~h}$. The dehydrated powders were transferred to a glove box charged with high-purity Ar. To examine the catalytic activity of the powders, each dehydrated powder sample (100 $\mathrm{mg}$ ) was transferred to a round-bottom flask. The reactions were carried out in a 25-mL round-bottom flask equipped with a water-cooled condenser and an oxygen inlet to introduce oxygen. The reaction mixture was continuously stirred using a magnetic stirrer. The temperature of the reactor was maintained at $95{ }^{\circ} \mathrm{C}$. In a typical reaction, the dehydrated catalyst powder (100 $\mathrm{mg}, 0.22 \mathrm{mmol}$ ) was first dispersed in DMF (20 $\mathrm{mL}$ ) by sonication. Subsequently, styrene (500 mg, $5 \mathrm{mmol}$ ) was introduced into the reaction system. The reaction was carried out at $95{ }^{\circ} \mathrm{C}$ with continuous bubbling of $\mathrm{O}_{2}(4 \mathrm{~mL} / \mathrm{min})$ into the reactor. After $4 \mathrm{~h}$ of reaction, the catalyst was removed from the reaction mixture by centrifugation and the products in the supernatant solution were analyzed by gas chromatography mass spectrometry. A reaction temperature of $95{ }^{\circ} \mathrm{C}$ and a reaction time of $4 \mathrm{~h}$ were chosen because conversion saturation could be obtained under these reaction conditions. The conversion is based on the amount of styrene consumed in the reaction mixture.

\section{Results and discussion}

\subsection{XRD analysis}

The crystallinity of the Co-E10- $n$ and Co-A6- $m$ powders was analyzed by XRD, and the patterns are shown in Fig. 2. All samples displayed characteristic diffraction patterns of ETS-10-type phase. In general, the $\mathrm{Co}^{2+}$ ion exchange did not affect the crystallinity of the catalysts except for the gradual slight decreases in the intensity of the diffraction peaks at $2 \theta=$ $12.16^{\circ}$ and $28.34^{\circ}$ and slight increases in the intensity of the peaks at $2 \theta=12.96^{\circ}, 17.88^{\circ}$, and $20.06^{\circ}$ with increasing degrees of ion exchange. Importantly, the $\mathrm{Co}^{2+}$ ion exchange did not induce any collapse of the Co-E10- $n$ and Co-A6- $m$ structures.

\subsection{SEM studies}

The SEM images of the Co-E10- $n$ and Co-A6- $m$ samples are shown in Fig. 3. As observed, the crystals adopted a truncated tetragonal bipyramidal structure and were rather uniform in size. The surfaces were very smooth, and secondary phases or unreacted gel were absent in the samples. The lengths, $L$, in the (110) and (001) directions were 200-300 nm for Co-E10- $n$ and 


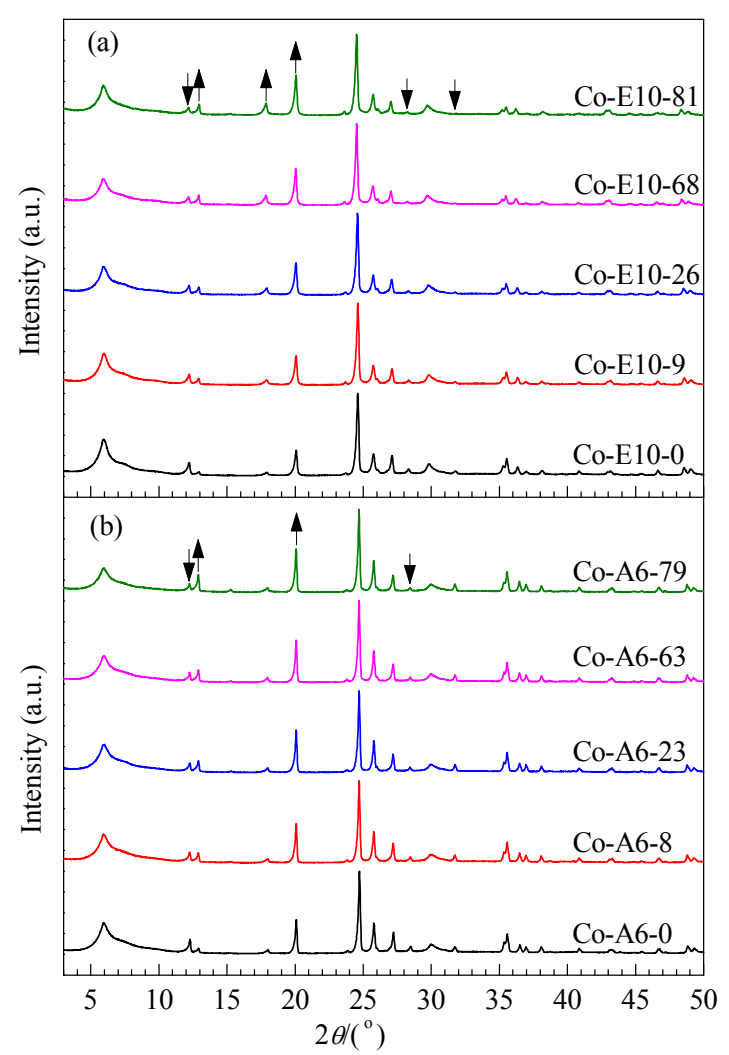

Fig. 2. XRD patterns of Co-E10- $n$ (a) and Co-A6- $m$ (b). Pristine ETS-10 and AM-6 denoted as Co-E10-0 and Co-A6-0, respectively.

\section{0-250 nm for Co-A6-m.}

\section{3. $\mathrm{N}_{2}$ adsorption-desorption analysis}

The pore structures of the Co-E10- $n$ and Co-A6- $m$ samples were studied by $\mathrm{N}_{2}$ sorption. The $\mathrm{N}_{2}$ sorption isotherms of the samples were measured within a relative pressure $\left(p / p_{0}\right)$ range of $10^{-6}$ to 0.998 ; the isotherms are shown in Fig. 4. As observed, all samples displayed Type I isotherms according to the classification of BET, which is typical of microporous materials. The BET surface areas of the Co-E10- $n$ samples $(n=0,9,26,68,81)$ were respectively $412,410,391,358$, and $337 \mathrm{~m}^{2} / \mathrm{g}$ and those of the Co-A6- $m$ samples $(m=0,8,23,63$, and 79) were respec-

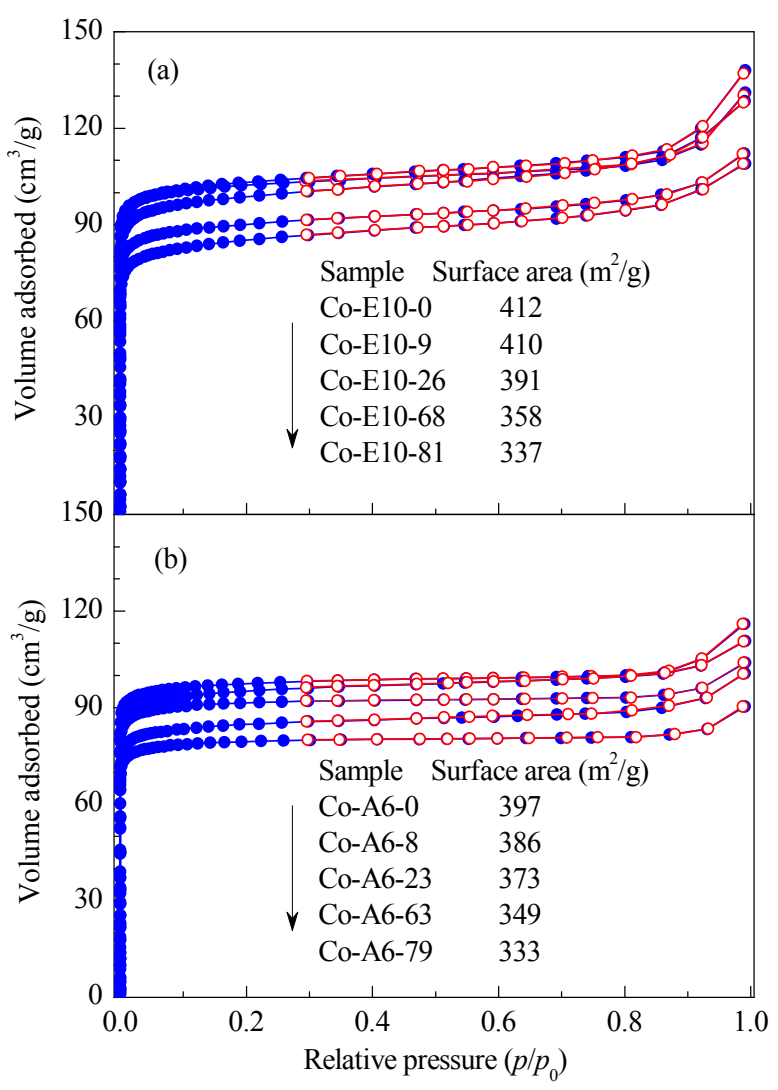

Fig. 4. $\mathrm{N}_{2}$ adsorption-desorption isotherms of Co-E10- $n$ (a) and Co-A6-m (b).

tively $397,386,373,349$, and $333 \mathrm{~m}^{2} / \mathrm{g}$. Thus, as deduced, as the degree of $\mathrm{Co}^{2+}$-ion exchange increased, the surface area gradually decreased. This trend indicated the onset of a slight structure collapse as the degree of $\mathrm{Co}^{2+}$ ion exchange increased, though the samples featured comparable XRD patterns and SEM results with no noticeable differences regardless of the ion exchange degree. Additionally, Co-A6-0 (pristine AM-6) displayed a similar surface area to that of previously reported high-quality AM-6 [21,22], thereby indicating that the crystallinity of Co-A6-0 is very high. The relative crystallinity, BET surface areas, and other structural information of the Co-E10- $n$ and Co-A6- $m$ samples are summarized in Table 1.

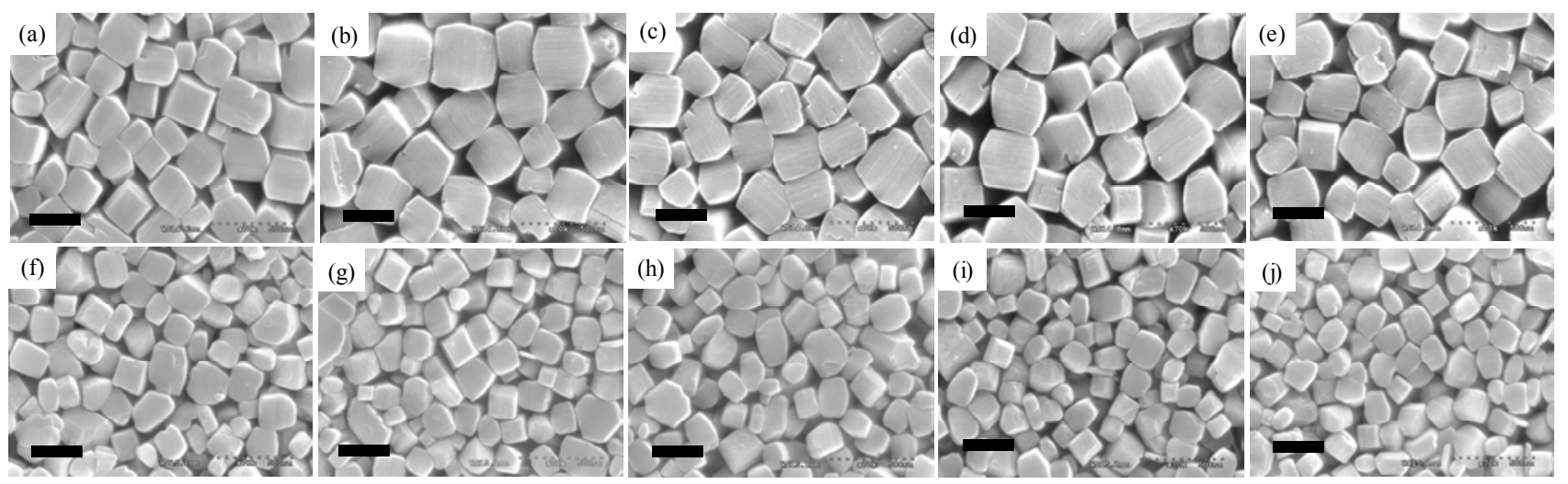

Fig. 3. SEM images of Co-E10- $n$ with $n=0$, pristine ETS-10 (a), 9 (b), 26 (c), 68 (d), and 81 (e) and of Co-A6- $m$ with $m=0$, pristine AM-6 (f), 8 (g), 23 (h), 63 (i), and 79 (j). Scale bar $=300 \mathrm{~nm}$. 
Table 1

Chemical compositions and physical properties of catalysts used in this study.

\begin{tabular}{|c|c|c|c|c|c|c|}
\hline Catalyst & Composition & $\begin{array}{c}\text { Degree of } \mathrm{Co}^{2+} \text { exchange } \\
(\%)\end{array}$ & Weight $\%$ of $\mathrm{Co}^{2+}$ & $\begin{array}{c}\text { Crystallinity } \\
(\%)\end{array}$ & $\begin{array}{l}\text { Surface area } \\
\left(\mathrm{m}^{2} / \mathrm{g}\right)\end{array}$ & $\begin{array}{l}\text { Raman band width } \\
\left(\mathrm{cm}^{-1}\right)\end{array}$ \\
\hline Co-E10-0 & $\mathrm{Na}_{1.6} \mathrm{~K}_{0.40} \mathrm{TiSi}_{5} \mathrm{O}_{13}$ & 0 & 0.0 & 100 & 412 & 29 \\
\hline Co-E10-9 & $\mathrm{Co}_{0.09} \mathrm{Na}_{1.43} \mathrm{~K}_{0.40} \mathrm{TiSi}_{5} \mathrm{O}_{13}$ & 9 & 1.1 & 96 & 410 & 30 \\
\hline Co-E10-26 & $\mathrm{Co}_{0.26} \mathrm{Na}_{1.10} \mathrm{~K}_{0.38} \mathrm{TiSi}_{5} \mathrm{O}_{13}$ & 26 & 3.4 & 92 & 391 & 31 \\
\hline Co-E10-68 & $\mathrm{Co}_{0.68} \mathrm{Na}_{0.35} \mathrm{~K}_{0.29} \mathrm{TiSi}_{5} \mathrm{O}_{13}$ & 68 & 8.8 & 87 & 358 & 43 \\
\hline Co-E10-81 & $\mathrm{Co}_{0.81} \mathrm{Na}_{0.17} \mathrm{~K}_{0.21} \mathrm{TiSi}_{5} \mathrm{O}_{13}$ & 81 & 10.5 & 83 & 337 & 50 \\
\hline Co-A6-0 & $\mathrm{Na}_{1.6} \mathrm{~K}_{0.40} \mathrm{VSi}_{5} \mathrm{O}_{13}$ & 0 & 0.0 & 100 & 397 & 10 \\
\hline Co-A6-8 & $\mathrm{Co}_{0.08} \mathrm{Na}_{1.45} \mathrm{~K}_{0.39} \mathrm{VSi}_{5} \mathrm{O}_{13}$ & 8 & 1.0 & 94 & 386 & 11 \\
\hline Co-A6-23 & $\mathrm{Co}_{0.23} \mathrm{Na}_{1.21} \mathrm{~K}_{0.33} \mathrm{VSi}_{5} \mathrm{O}_{13}$ & 23 & 3.0 & 90 & 373 & 14 \\
\hline Co-A6-63 & $\mathrm{Co}_{0.63} \mathrm{Na}_{0.43} \mathrm{~K}_{0.31} \mathrm{VSi}_{5} \mathrm{O}_{13}$ & 63 & 8.1 & 89 & 349 & 27 \\
\hline Co-A6-79 & $\mathrm{Co}_{0.79} \mathrm{Na}_{0.18} \mathrm{~K}_{0.24} \mathrm{VSi}_{5} \mathrm{O}_{13}$ & 79 & 10.2 & 81 & 333 & 38 \\
\hline
\end{tabular}

Pristine ETS-10 and AM-6 denoted as Co-E10-0 and Co-A6-0, respectively.

\subsection{Raman spectroscopy analysis}

The Raman spectra of the Co-E10- $n$ and Co-A6- $m$ samples are shown in Fig. 5. The Raman spectra of the longitudinal (along the wire) vibration modes of the -Ti-O-Ti-O- and -V-O-V-O- chains provide highly useful information on the quality and local environment of the $\mathrm{TiO}_{3}{ }^{2-}$ and $\mathrm{VO}_{3}{ }^{2-}$ quantum wires in Co-E10- $n$ and Co-A6- $m$, respectively. The $v_{\max }$ value is related to the length of the quantum wires, and decreased as the length increased [22]. The high-quality ETS-10 crystals displayed $v_{\max }$ in the $721-724 \mathrm{~cm}^{-1}$ region $[23,24]$. The intensity of the longitudinal vibration is related to the number of quantum wires and increased as the number increased. The

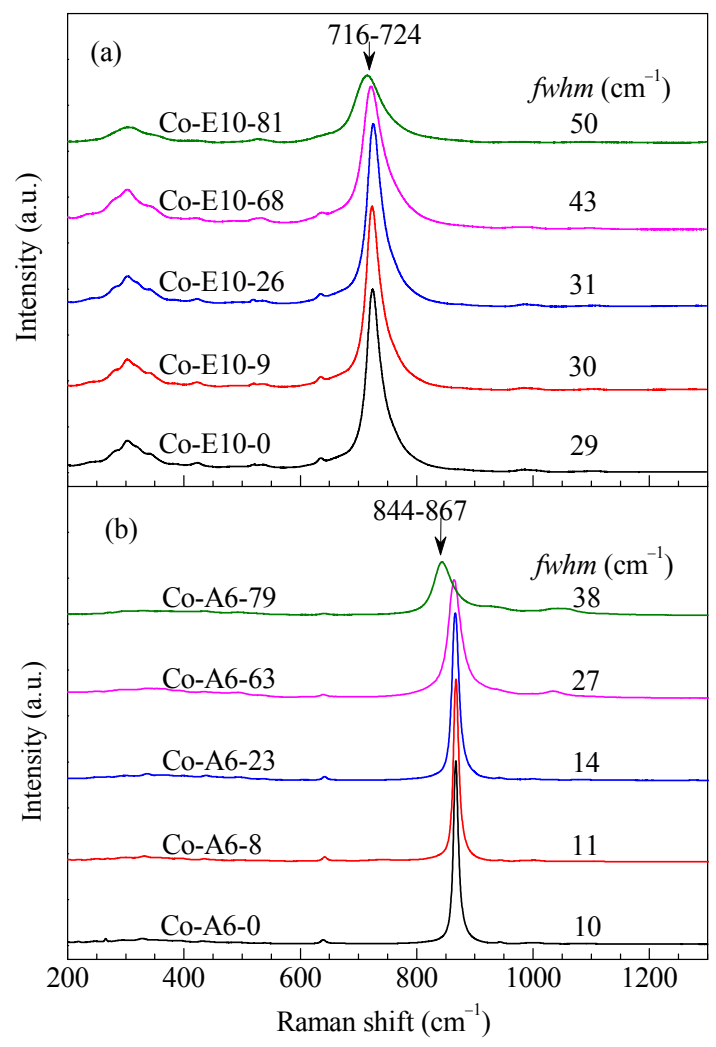

Fig. 5. Raman spectra of Co-E10- $n$ (a) and Co-A6-m (b). bandwidth (fwhm) is related to the homogeneity of the length of the quantum wires $(I)$ and decreased as the homogeneity of $l$ increased. Reported values of the bandwidth have been observed between 23 and $120 \mathrm{~cm}^{-1}$.

The obtained $\nu_{\max }$ value at $724 \mathrm{~cm}^{-1}$ for Co-E10- $n(n=0,9$, 26,68 ) indicated that the average length of the titanate quantum wires in the Co-E10- $n$ crystals remained unchanged regardless of the $\mathrm{Co}^{2+}$ exchange degree up to $68 \%$. In contrast, Co-E10-81 displayed a shift in $v_{\max }$ to a lower wavenumber region, indicating that the average length of the titanate quantum wires in Co-E10-81 was shorter than that in Co-E10- $n(n=$ $0,9,26,68)$. The bandwidths of Co-E10- $n(n=0,9,26,68,81)$ were $29,30,31,43$, and $50 \mathrm{~cm}^{-1}$, respectively. This finding indicates that though the length homogeneity of the titanate quantum wires in pristine ETS-10 (Co-E10-0) was high, it gradually decreased with increasing degrees in $\mathrm{Co}^{2+}$ ion exchange. Thus, the introduction of $\mathrm{Co}^{2+}$ led to disconnection of the titanate quantum wires.

The high-quality AM-6 displayed a Raman shift, corresponding to the longitudinal vibration of the vanadate quantum wires, at $870 \mathrm{~cm}^{-1}$ with a bandwidth of $10 \mathrm{~cm}^{-1}[20,21]$. The $v_{\max }$ and fwhm of Co-A6-0 (pristine AM-6) were 867 and 10 $\mathrm{cm}^{-1}$, respectively, which was indicative of the very high crystallinity of Co-A6-0. The $v_{\max }$ value of Co-A6- $n(n=8,23,63)$ was also $870 \mathrm{~nm}$. This finding indicated that the average length of the vanadate quantum wires remained unchanged regardless of the degree of $\mathrm{Co}^{2+}$ exchange up to $63 \%$. In contrast, Co-A6-79 displayed a $v_{\max }$ shift to a lower wavenumber region, thereby indicating that the average length of the vanadate quantum wires in this sample was shorter than that in Co-A6- $n$ $(n=0,8,23,63)$. The bandwidths of Co-A6- $n(n=0,8,23,63$, 79) were $10,11,14,27$, and $38 \mathrm{~cm}^{-1}$, respectively. This finding indicated that though the length homogeneity of the vanadate quantum wires in pristine AM-6 (Co-A6-0) was high, it gradually decreased with increasing degrees of $\mathrm{Co}^{2+}$ ion exchange. Likewise, the introduction of $\mathrm{Co}^{2+}$ led to disconnection of the vanadate quantum wires.

\subsection{UV-visible spectroscopy analysis}

Pristine ETS-10 (Co-E10-0) was colorless unlike the corre- 

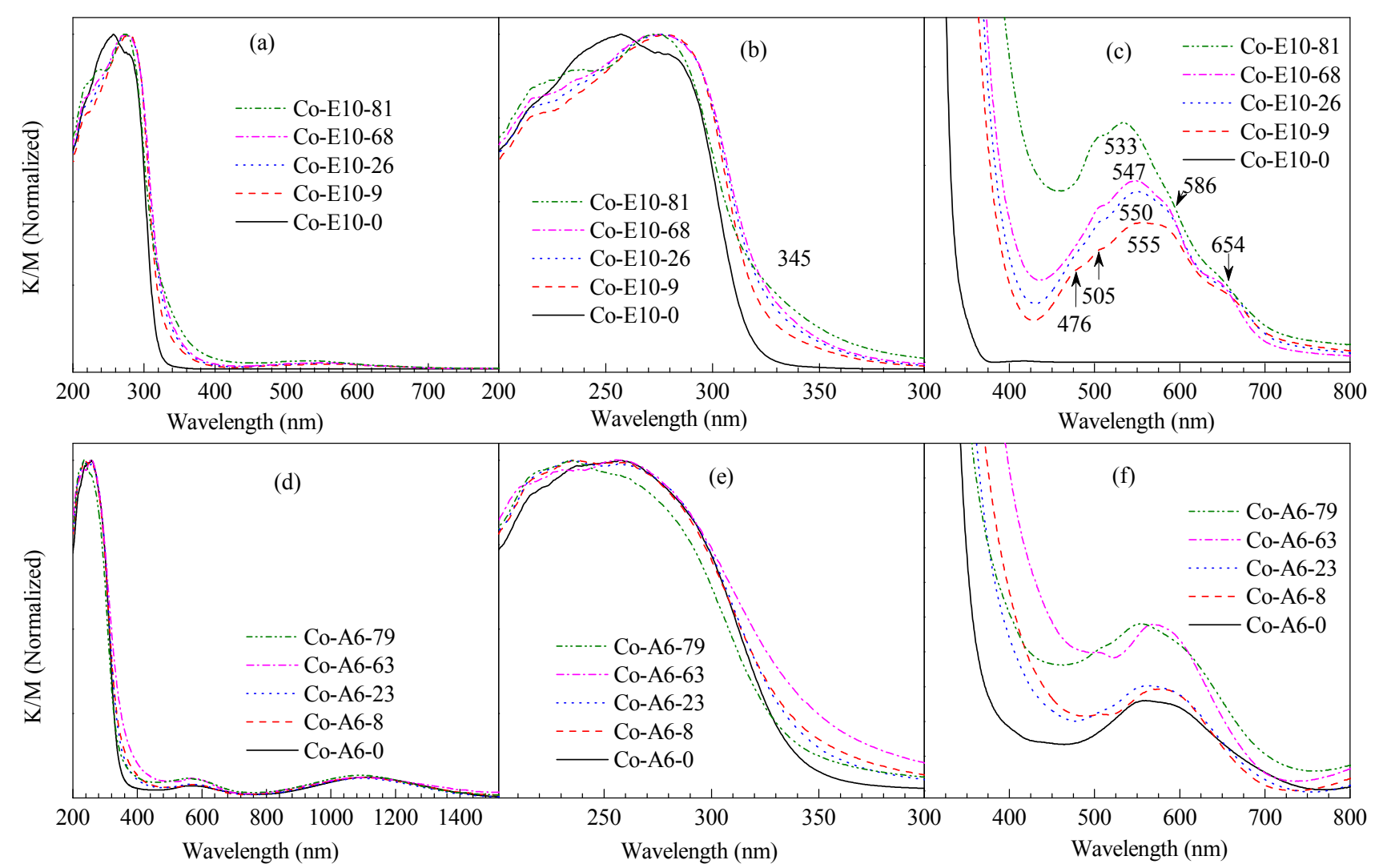

Fig. 6. Diffuse reflectance UV-Vis spectra of Co-E10- $n$ in the spectral regions of 200-800 (a), 200-400 (b), and 300-800 nm (c) and Co-A6- $m$ in the spectral regions of 200-1500 (d), 200-400 (e), and 300-800 nm (f), respectively.

sponding $\mathrm{Co}^{2+-}$ exchanged samples $(n=9,26,68,81)$ that were light pink. The UV-visible spectra of the Co-E10- $n$ samples are shown in Figs. 6(a)-(c) in the spectral regions of 200-800, 200-400, and 300-800 $\mathrm{nm}$. The UV-visible spectrum of Co-E10-0 displayed absorption bands below $340 \mathrm{~nm}$, and these of Co-E10- $n(n=9,26,68,81)$ displayed additional bands at $\sim 350$ and $\sim 520 \mathrm{~nm}$. These new bands were obtained owing to the incorporated $\mathrm{Co}^{2+}$ ions. The intensity of the bands increased with increasing degrees of $\mathrm{Co}^{2+}$ exchange. Regarding the visible band, the absorption band blue shifted with increasing degrees of $\mathrm{Co}^{2+}$ exchange, indicating that it has the framework oxygen to $\mathrm{Co}^{2+}$ charge transfer nature.

Pristine AM-6 (Co-A6-0) was pale yellow, and the corresponding $\mathrm{Co}^{2+-}$ exchanged samples $(m=8,23,63,79)$ were light gray. The UV-visible spectra of the Co-A6- $m$ samples are shown in Figs. 6(d)-(f) in the spectral regions of 200-1500, 200-400, and $300-800 \mathrm{~nm}$. The UV-visible spectrum of pristine AM-6 (Co-A6-0) displayed absorption maximums $\left(\lambda_{\max }\right)$ at $238(0.98)$, 260 (1), 558 (0.036), and 1113 (0.061) nm (the relative intensity of the bands are shown in parentheses). The spectra of Co-A6- $m(m=8,23,63,79)$ displayed additional absorption bands at $\sim 350$ and $\sim 520 \mathrm{~nm}$ owing to the incorporation of $\mathrm{Co}^{2+}$.

\subsection{Catalytic activity studies}

The catalytic activities of Co-E10- $n$ and Co-A6- $m$ were as- sessed toward the oxidation of styrene with molecular oxygen (Fig. 7, Table 2). In both cases, styrene epoxide (E) and benzaldehyde (B) were obtained as the major products with trace amounts of phenylacetaldehyde. The overall rate of conversion was between 5.4 and $12.4 \mathrm{~mol} \cdot \mathrm{g}^{-1} \cdot \mathrm{h}^{-1}$. Interestingly, even in the absence of $\mathrm{Co}^{2+}$, both Co-E10-0 (pristine ETS-10) and Co-A6-0 (pristine AM-6) were catalytically active toward the oxidation of styrene to $\mathrm{E}$ and $\mathrm{B}$ with molecular oxygen. This finding suggested that both $\mathrm{Ti}$ and $\mathrm{V}$ could also catalyze the reaction. However, the activity increased upon increasing addition of $\mathrm{Co}^{2+}$ content.

Comparison between the two sets of reaction profiles (Figs. $7(\mathrm{a})$ and (b)) revealed that the Co-E10- $n$ catalysts were more active than the Co-A6- $m$ catalysts. The higher catalytic activity was likely due to the slightly larger pore size of ETS-10 relative to that of AM-6. Furthermore, as observed, a $\mathrm{Co}^{2+}$ exchange level of $26 \%$ was required to reach $100 \%$ conversion using the ETS-10 catalyst system. Contrarily, a $\mathrm{Co}^{2+}$ exchange level of $63 \%$ was required to achieve $100 \%$ conversion using the AM-6 catalyst system. In both catalyst systems (Co-E10- $n$ and Co-A6- $m$ ), the reaction rates increased, while the E/B ratio decreased sharply with increasing degrees of $\mathrm{Co}^{2+}$ ion exchange (Fig. 7(c)). The highest E/B ratio (2.1) was obtained using Co-E10-0 that was lower than those observed using other catalysts (SrCoX18, BaCoX19, Co-SBA-15-20-5.2, Co-Beta, and Co-SAPO-34), of which the E/B ratios were in the range of 3.3-5.7 (Table 3). Accordingly, we could deduce that the 

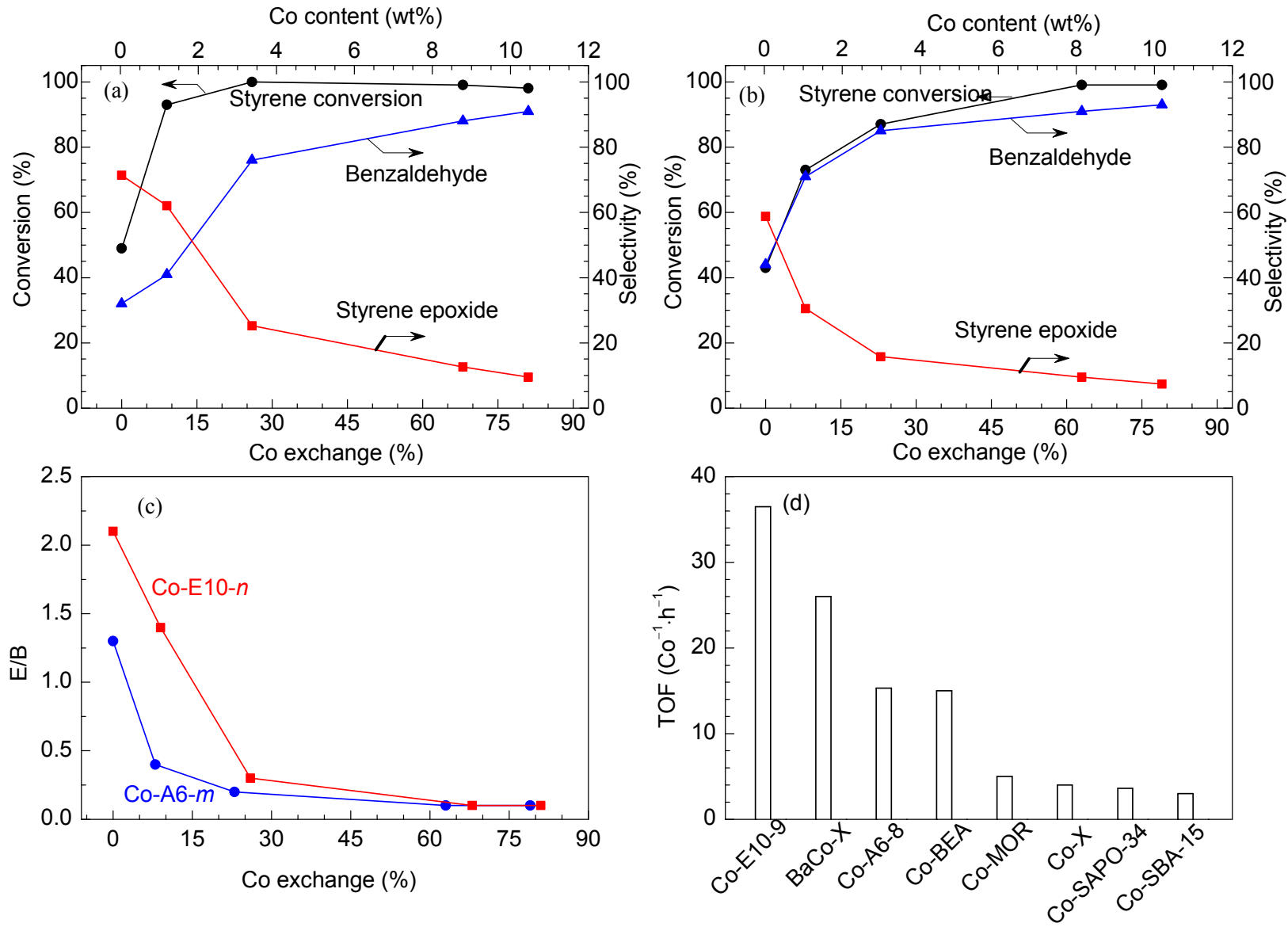

Fig. 7. Plots of the conversion and the major products with respect to the degree of $\mathrm{Co}^{2+}$ ion in Co-E10-n (a) and Co-A6- $m$ (b). Plots of the E/B ratio with respect to the degree of $\mathrm{Co}^{2+}$ ion in Co-E10- $n$ and Co-A6- $m$ (c). Comparison of the TOF $\left(\mathrm{Co}^{-1} \cdot \mathrm{h}^{-1}\right)$ of various catalysts for styrene to styrene epoxide conversion (d).

Co-E10- $n$ and Co-A6- $m$ catalysts were more suited for application in the selective production of $\mathrm{B}$ over that of $\mathrm{E}$ from styrene and molecular oxygen. In particular, the $\mathrm{E} / \mathrm{B}$ ratio became very small (0.1) when the highly Co ${ }^{2+-}$ exchanged ETS-10 and AM-6 (Co-E10-68, Co-E10-81, Co-A6-63, and Co-A6-79) were used as the catalysts. Nevertheless, it is interesting to note that in the case of Co-E10-9, the turnover frequency per Co atom per hour was 36.3 , which was higher than those obtained from the other catalysts studied (Table 3 and Fig. 7(d)).

The catalytic activity of ETS-10 exchanged with other transition metal ions, such as $\mathrm{Cr}^{3+}, \mathrm{Mn}^{2+}, \mathrm{Fe}^{3+}, \mathrm{Ni}^{2+}, \mathrm{Cu}^{2+}$, and $\mathrm{Zn}^{2+}$, was also examined. However, the resulting activities were considerably lower than that of the Co-E10- $n$ catalysts, with $\mathrm{Cr}^{3+}$-ETS-10 displaying a conversion of $11 \%$ and E selectivity of $55 \%$.

Table 2

Oxidation of styrene with air over Co-E10- $n$ and Co-A6- $m$ catalysts.

\begin{tabular}{|c|c|c|c|c|c|c|c|}
\hline \multirow{2}{*}{ Catalyst } & \multirow{2}{*}{ Conversion (\%) } & \multirow{2}{*}{$\begin{array}{c}\text { Rate } \\
\left(\mathrm{mmol} \cdot \mathrm{g}^{-1} \cdot \mathrm{h}^{-1}\right)\end{array}$} & \multicolumn{2}{|c|}{ Selectivity (\%) } & \multirow{2}{*}{$\mathrm{E} / \mathrm{B}$} & \multicolumn{2}{|c|}{$\operatorname{TOF}\left(\mathrm{Co}^{-1} \cdot \mathrm{h}^{-1}\right)$} \\
\hline & & & $\mathrm{E}$ & $\mathrm{B}$ & & $\mathrm{E}$ & $\mathrm{B}$ \\
\hline Blank & $<2.5$ & - & 45 & 65 & 0.69 & - & - \\
\hline Co-E10-0 & 49 & 6.1 & 68 & 32 & 2.1 & - & - \\
\hline Co-E10-9 & 93 & 11.6 & 59 & 41 & 1.4 & 36.3 & 25.2 \\
\hline Co-E10-26 & 100 & 12.5 & 24 & 76 & 0.3 & 5.2 & 16.5 \\
\hline Co-E10-68 & 99 & 12.4 & 12 & 88 & 0.1 & 1.0 & 7.3 \\
\hline Co-E10-81 & 98 & 12.3 & 9 & 91 & 0.1 & 0.6 & 6.3 \\
\hline Co-A6-0 & 43 & 5.4 & 56 & 44 & 1.3 & - & - \\
\hline Co-A6-8 & 73 & 9.1 & 29 & 71 & 0.4 & 15.0 & 36.7 \\
\hline Co-A6-23 & 87 & 10.9 & 15 & 85 & 0.2 & 3.2 & 18.2 \\
\hline Co-A6-63 & 99 & 12.4 & 9 & 91 & 0.1 & 0.8 & 8.2 \\
\hline Сo-A6-79 & 99 & 12.4 & 7 & 93 & 0.1 & 0.5 & 6.7 \\
\hline
\end{tabular}

Reaction conditions: dehydrated catalyst $100 \mathrm{mg}, 95^{\circ} \mathrm{C}$, styrene $5 \mathrm{mmol}$, DMF $20 \mathrm{~mL}, \mathrm{O}_{2} \sim 4 \mathrm{~mL} / \mathrm{min}, 4 \mathrm{~h}$. Pristine ETS-10 and AM- 6 denoted as Co-E10-0 and Co-A6-0, respectively. 
Table 3

Catalytic performances of the catalysts extracted from the literature.

\begin{tabular}{|c|c|c|c|c|c|c|c|c|}
\hline \multirow{2}{*}{ Catalyst } & \multirow{2}{*}{ Conversion (\%) } & \multirow{2}{*}{$\begin{array}{c}\text { Rate } \\
\left(\mathrm{mmol} \cdot \mathrm{g}^{-1} \cdot \mathrm{h}^{-1}\right)\end{array}$} & \multicolumn{2}{|c|}{ Selectivity (\%) } & \multirow{2}{*}{$\mathrm{E} / \mathrm{B}$} & \multicolumn{2}{|c|}{ TOF $\left(\mathrm{Co}^{-1} \cdot \mathrm{h}^{-1}\right)$} & \multirow{2}{*}{ Ref. } \\
\hline & & & $E$ & $\mathrm{~B}$ & & $E$ & $\mathrm{~B}$ & \\
\hline $\mathrm{Co}^{2+-} \mathrm{X}(8.8 \mathrm{wt} \%)$ & 45 & 5.6 & 65.0 & 35.0 & 1.9 & 4.0 & 0.04 & [5] \\
\hline SrCoX18 & 100 & 12.5 & 85.0 & 15.0 & 5.7 & 20.0 & 0.03 & [7] \\
\hline BaCoX19 & 100 & 12.5 & 83.0 & 17.0 & 4.9 & 26.0 & 0.04 & [7] \\
\hline Co-SBA-15-20-5.2 & 92.4 & 4.1 & 63.2 & 15.6 & 4.1 & 3.0 & 0.79 & [10] \\
\hline Co-Beta & 35.5 & 2.1 & 72.8 & 21.9 & 3.3 & 15.3 & 3.85 & [13] \\
\hline Co-SAPO-34 & 37.8 & 1.9 & 76.7 & 17.5 & 4.4 & 3.6 & 0.81 & [14] \\
\hline Co-MOR & 10.3 & 0.6 & 66.7 & 33.3 & 2.0 & 5.0 & 1.89 & [15] \\
\hline
\end{tabular}

\subsection{Recycling studies}

In the subsequent studies, Co-E10-9 and Co-A6-79 were chosen as the model catalysts. Following catalysis, the catalysts were recovered from the corresponding reaction mixtures by centrifugation and washed sequentially with copious amounts of DMF and water. The catalysts were then dried in an oven at $90{ }^{\circ} \mathrm{C}$ for $1 \mathrm{~h}$, and finally vacuum dried at $150{ }^{\circ} \mathrm{C}$ for $10 \mathrm{~h}$. The dried catalysts were reused in subsequent catalysis reactions. As noted, the conversion and selectivity remained unchanged after four catalytic cycles (Fig. 8), thereby indicating that Co-E10-9 and Co-A6-79 are highly stable and can be used efficiently with no loss in catalytic activity.

\section{8. $\quad$ Proposed reaction mechanism}

Based on the current study and other literature reports $[7,10]$, a plausible reaction mechanism for the epoxidation of styrene with molecular oxygen over $\mathrm{Co}^{2+}$-containing catalysts is shown in Scheme 1. It is expected that DMF molecules coordinate to the extraframework $\mathrm{Co}^{2+}$ cations $(\mathrm{ZO}) \mathrm{Co}^{2+}$ present in the zeolite pores through the oxygen atom of DMF resulting in the formation of $(\mathrm{DMF}, \mathrm{ZO}) \mathrm{Co}^{2+}$. The $\mathrm{Co}^{2+}$ cation in $(\mathrm{DMF}, \mathrm{ZO}) \mathrm{Co}^{2+}$ is electron rich because it is coordinated to the negatively charged framework oxygen atoms. Consequently, $(\mathrm{DMF}, \mathrm{ZO}) \mathrm{Co}^{2+}$ attracts $\mathrm{O}_{2}$. Subsequently, an oxygen molecule $\left(\mathrm{O}_{2}\right)$ coordinates to the $\mathrm{Co}^{2+}$ ion, resulting in the formation of a cobalt superoxo complex (DMF,ZO)Co ${ }^{3+-00}$ (I). A styrene molecule coordinates to I through the vinyl group to form

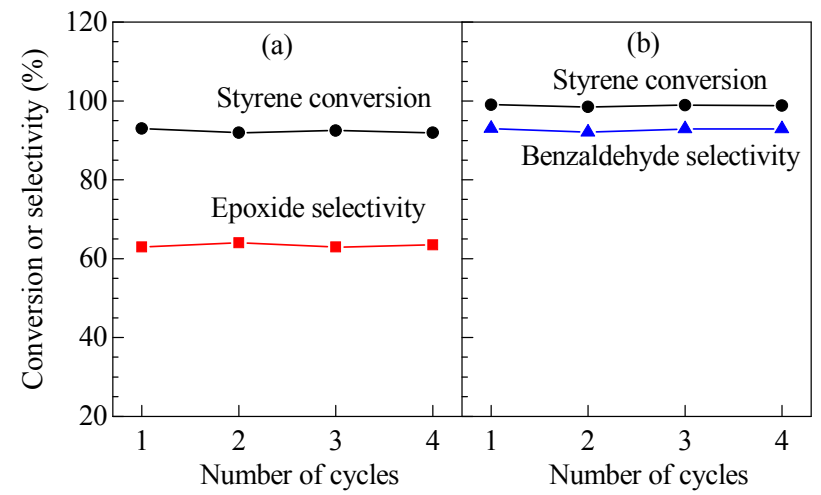

Fig. 8. Recycle test of the catalysts in styrene conversion with molecular oxygen on Co-E10-9 (a) and Co-A6-79 (b). Reaction conditions: same as Table 2 .
(DMF, ZO, Styrene)Co ${ }^{3+-0 O \bullet(I I) . ~ T h r o u g h ~ m i g r a t o r y ~ i n s e r t i o n, ~}$ II rearranges to an intermediate III. Then, III disintegrates to the cyclic peroxide IV and (DMF,ZO) $\mathrm{Co}^{2+}$. The cyclic peroxide IV then undergoes two different types of reactions: (1) thermal decomposition to benzaldehyde and formaldehyde and (2) transfer of an oxygen atom to another styrene molecule to form two styrene epoxide molecules.

\section{Conclusions}

Pristine ETS-10 (Co-E10-0) and AM-6 (Co-A6-0) displayed catalytic activities toward the oxidation of styrene with molecular $\mathrm{O}_{2}$ to styrene epoxide and benzaldehyde in DMF. The corresponding $\mathrm{Co}^{2+}$-exchanged powders showed higher catalytic activities, and the activity increased with increasing degrees of ion exchange. Contrary to the conversion, the E/B ratio decreased with increasing $n$ or $m$ reaching 0.1 . Therefore, highly

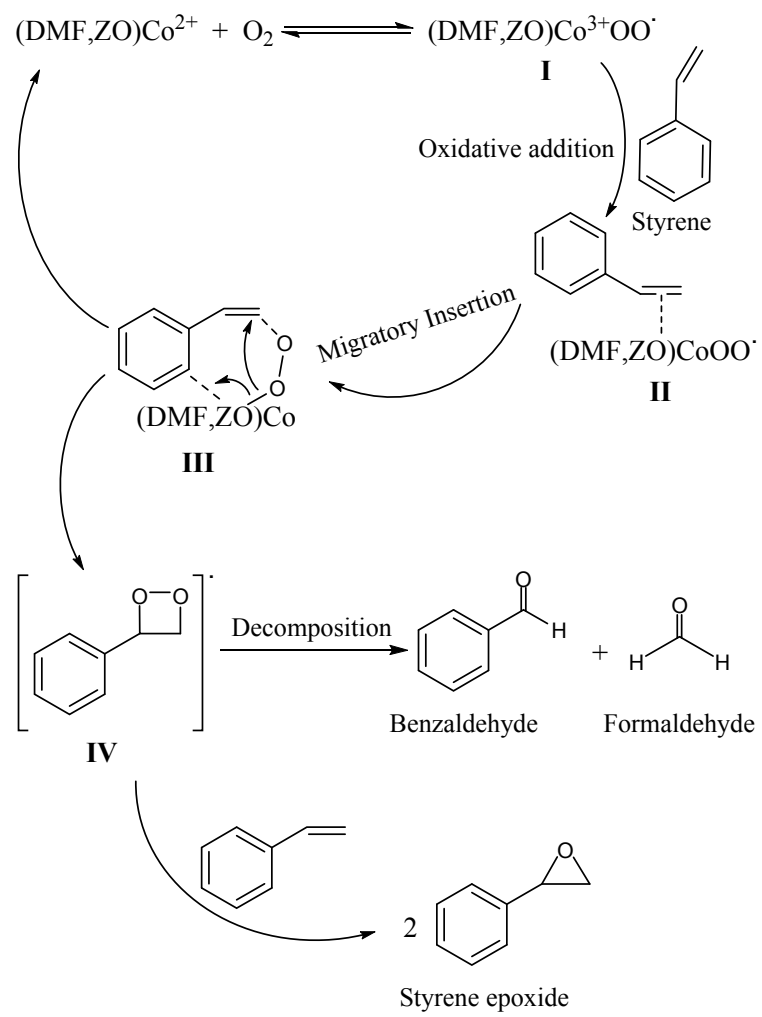

Scheme 1. A possible reaction mechanism for the oxidation of styrene into epoxide and benzaldehyde with air as the oxidant. ZO denotes E10- $n$ and A6- $m$. 


\section{Graphical Abstract}

Chin. J. Catal., 2015, 36: 897-905 doi: 10.1016/S1872-2067(15)60864-6

\section{Co-ETS-10 and Co-AM-6 as active catalysts for the oxidation of styrene to styrene oxide and benzaldehyde using molecular oxygen}

Shuvo Jit Datta, Kyung Byung Yoon*

Sogang University, Korea

ETS-10, AM-6, and their corresponding $\mathrm{Co}^{2+-}$ exchanged forms were examined as catalysts toward the oxidation of styrene in oxygen atmosphere. The conversion increased, whereas the styrene epoxide/benzaldehyde product ratio decreased with increasing degrees of $\mathrm{Co}^{2+}$ exchange. In the absence of $\mathrm{Co}^{2+}$, pristine ETS-10 and AM- 6 were catalytically active toward the formation of styrene epoxide.

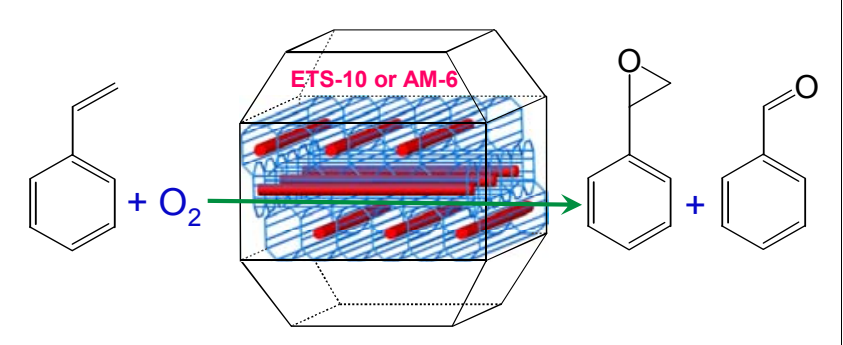

[9] Jinka K M, Pai S M, Newalkar B L, Choudary N V, Jasra R V. Catal Commun, 2010, 11: 638

$\mathrm{Co}^{2+-}$ exchanged ETS-10 and AM-6 (Co-E10-68, Co-E10-81, Co-A6-63, Co-A6-79) are very good catalysts for the selective production of $\mathrm{B}$ from styrene and molecular $\mathrm{O}_{2}$. The highest turnover frequency obtained was $36.3 \mathrm{Co}^{-1} \cdot \mathrm{h}^{-1}$, which was the highest value obtained among the different $\mathrm{Co}^{2+}$-exchanged zeolites and mesoporous silica studied in this work.

\section{Acknowledgments}

This work was supported by the Korea Center for Artificial Photosynthesis, funded by the Ministry of Science, ICT and Future Planning through the National Research Foundation of Korea [no. 2009-0093886 and no. 2012R1A2A3A01009806]. We also thank J. Y. Lee for the help in drawing Fig. 1.

\section{References}

[1] Joergensen K A. Chem Rev, 1989, 89: 431

[2] Neumann R, Dahan M. Nature, 1997, 388: 353

[3] Hill C L. Nature, 1999, 401: 436

[4] Ishii Y, Sakaguchi S, Iwahama T. Adv Synth Catal, 2001, 343: 393

[5] Tang Q H, Wang Y, Liang J, Wang P, Zhang Q H, Wan H L. Chem Commun, 2004: 440

[6] Tang Q H, Zhang Q H, Wu H L, Wang Y.J Catal, 2005, 230: 384

[7] Sebastian J, Jinka K M, Jasra R V.J Catal, 2006, 244: 208

[8] Patil M V, Yadav M K, Jasra R V.J Mol Catal A, 2007, 277: 72
[10] Cui H T, Zhang Y, Zhao L F, Zhu Y L. Catal Commun, 2011, 12: 417

[11] Xu G, Xia Q H, Lu X H, Zhang Q Zhan H J, J Mol Catal A, 2007, 266: 180

[12] Qi B, Lu X H, Fang S Y, Lei J, Dong Y L, Zhou D, Xia Q H, J Mol Catal A, 2011, 334: 44

[13] Tang B, Lu X H, Zhou D, Lei J, Niu Z H, Fan J, Xia Q H. Catal Commun, 2012, 21: 68

[14] Tang B, Lu X H, Zhou D, Tian P, Niu Z H, Zhang J L, Chen X, Xia Q H. Catal Commun, 2013, 3: 42

[15] Zhou D, Tang B, Lu X H, Wei X L, Li K, Xia Q H. Catal Commun, 2014, 45: 124

[16] Wei X L, Lu X H, Ma X T, Peng C, Jiang H Z, Zhou D, Xia Q H, Catal Commun, 2015, 61: 48

[17] Kuznicki S M. US Patent 4853202. 1989

[18] Anderson M W, Terasaki O, Ohsuna T, Philippou A, MacKay S P, Ferreira A, Rocha J, Lidin S. Nature, 1994, 367: 347

[19] Anderson M W, Terasaki O, Ohsuna T, Malley P J O, Philippou A, MacKay S P, Ferreira A, Rocha J, Lidin S. Philos Mag B, 1995,71: 813

[20] Rocha J, Brandao P, Lin Z, Anderson M W, Alfredsson V, Terasaki O. Angew Chem Int Ed, 1997, 36: 100

[21] Datta S J, Yoon K B. Angew Chem Int Ed, 2010, 49: 4971

[22] Datta S J, Yoon K B. J Am Chem Soc, 2012, 134: 17202

[23] Jeong N C, Lee M H, Yoon K B. Angew Chem Int Ed, 2007, 46: 5868

[24] Datta S J, Yoon K B. Catal Today, 2013, 204: 60 